\title{
Elecciones, ciudadanía y poder institucional: El caso de la Universidad Nacional de Costa Rica
}

Recibido: 23 de abril 2018

Revisado: 28 de agosto 2018 Aprobado: 19 de octubre 2018

Carlos Eduardo Cruz Meléndez

Costarricense, máster en sociología por la Universidad de Costa Rica; además cuenta con estudios en antropología, informática y filosofía; es académico en propiedad de la Facultad de Ciencias Sociales de la Universidad Nacional (Costa Rica) desde 1980, ocupando la coordinación del Centro de Información Documental en Ciencias Sociales (CIDCSO). Correo electrónico: carlos.cruz.melendez@una.cr

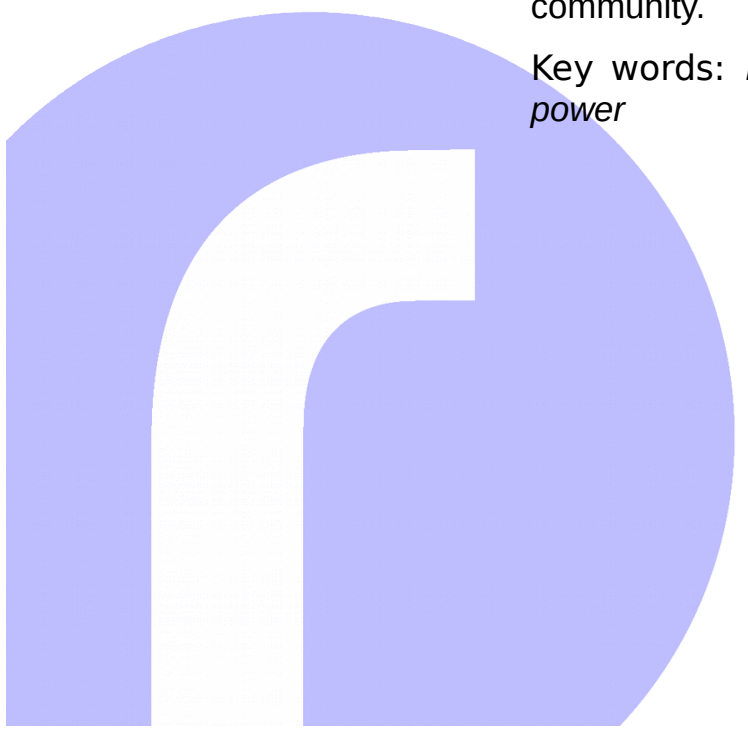

http://investiga.uned.ac.cr/rupturas/

Rev. Rupturas 8(2), Costa Rica, Jul-Dic 2018. ISSN 2215-2466. pp 219-242.
Resumen: Para agosto de 2015 entró en vigor el nuevo Estatuto Orgánico de la Universidad Nacional (Costa Rica). Tal normativa se gestó en el IV Congreso Universitario, habiendo sido uno de los temas de discusión la "democratización" de la Institución. En este artículo, se reflexiona sobre los fundamentos de la poliarquía universitaria, con base en la figura del "ciudadano universitario" y los cambios que hubo en las relaciones con el poder y responsabilidad de dirigir la Universidad. Se muestra cómo la aplicación de las nuevas disposiciones, lejos de democratizar la Universidad, han conllevado un enorme retroceso en la participación electoral de los estudiantes y pobres avances en la incorporación de los trabajadores interinos como miembros políticos plenos de la comunidad universitaria.

Palabras clave: Universidad Nacional; poliarquía; ciudadanía universitaria; elecciones; poder

\section{Elections, Citizenship and Institutional Power: The Case of Universidad Nacional de Costa Rica}

Abstract: By August 2015, the new Organic Statute of the National University (Costa Rica) came into force. These regulations were developed in the 4th University Congress, being one of the topics of discussion the "democratization" of the Institution. This article ponders over the fundaments of the academic polyarchy, focusing on the figure of the "academic citizen" and the changes that occurred in the relationship with the power and responsibility of managing the University. Showing how the application of the new provisions far from democratizing the University have led to a huge setback in the electoral participation of students and poor progress in the incorporation of interim workers as full political members of the academic community.

Key words: National University; polyarchy; unversity citizenship; elections; power 


\section{Introducción}

El individuo presuntamente portador de la naturaleza humana es una construcción social de la modernidad; una invención tan alienante como libertaria, pues si su irrupción de facto y de jure desvaloriza colectividades y rompe lazos solidarios, también arroja nueva luz sobre la pluralidad, al obligarnos a reconocer en los "otros" a un "nosotros"; no como en los tiempos de particularismo tribal cuando, por definición, los "otros" ni eran "hombres verdaderos", sino auténticos pares, cuando menos en tanto que compartimos la condición humana. $Y$ no estoy hablando de una naturaleza innata y trascendente, una abstracción fetichizada que encubre metafísicamente las desigualdades y diferencias estigmatizantes realmente existentes, sino de una condición humana hecha a mano, construida socialmente en la confrontación y/o a la solidaridad de los diversos (Bartra 2007, 185).

1. En todos los casos siempre hay otra serie de requisitos adicionales y distintos entre una institución y otra, tales como si el nombramiento del trabajador es en propiedad o no, si la persona trabaja a tiempo completo o no, si el estudiante lleva una determinada carga académica o no, etc.
En Costa Rica, las universidades públicas gozan de una autonomía plena que les permite "darse su organización y gobierno propios", según lo establece el Artículo 84 de la Constitución Política. Con esta potestad, las distintas universidades estatales han adoptado variantes de un gobierno de tipo "republicano" en la tradición liberal burguesa. La diferencia entre ellas radica en aspectos como la definición de quienes son "ciudadanos" y quienes no lo son dentro de cada comunidad universitaria, esto es, quienes tienen derecho a votar y quienes no en el seno de la respectiva "república universitaria" o acerca del peso relativo que tiene el voto de los distintos estamentos de las y los ciudadanos universitarios a la hora de tomar una decisión de política institucional o elegir una determinada autoridad institucional como, por ejemplo, escoger el rector o la rectora de la universidad o el decano o decana de una facultad. Así, a manera de ilustración, en la Universidad Nacional (UNA), los ciudadanos son las y los trabajadores académicos. ${ }^{1}$ Les corresponde a los votos de los académicos como estamento un peso relativo del 60 por ciento 
del total, a las y los trabajadores administrativos un peso relativo como estamento del 15 por ciento, en tanto que a los y las estudiantes como colectivo les corresponde el restante 25 por ciento. En el caso de la Universidad de Costa Rica (UCR), los trabajadores administrativos no son ciudadanos, y el derecho de votar se reparte en un peso relativo de un 75 por ciento para el estamento de los académicos y en un 25 por ciento para los estudiantes. En la Universidad Estatal a Distancia (UNED), a los académicos les corresponde una cuota de poder electoral del 65 por ciento, los trabajadores administrativos tienen por su parte un peso relativo del 30 por ciento, y el restante 15 por ciento lo tienen los estudiantes. Pero también hay diferencia en los mecanismos para ejercer el voto, como puede ser el caso del voto universal y directo: todos los individuos de cada uno de los estamentos pueden sufragar o existen procedimientos de un voto diferido por medio de la designación de representantes, quienes son los que en última instancia votan. Así, pues, el contenido y carácter procedimental democrático, "poliarquía", en las distintas "repúblicas universitarias" varía, y con ello se puede abrir la discusión sobre cuál "organización y gobierno propios" es más o menos "democrático". ${ }^{2}$ El tema de la presente reflexión es si hubo o no una democratización de la vida institucional en la UNA a raíz de los cambios introducidos sobre la "participación ciudadana" en su reciente "carta magna", o sea, en su nuevo Estatuto Orgánico de 2015.

En la tradición liberal burguesa y en términos generales, cada individuo es un ciudadano y cada ciudadano es un voto, como lo resalta Armando Bartra en la cita que se hace arriba como epígrafe. Un empoderamiento político del "individuo" que ciertamente conlleva una dimensión libertaria, pero también sobrelleva contradictoriamente la negación de la identidad como colectividad. Y en el caso de la UNA, como se mostrará luego, la reivindicación del voto universal por parte de los estudiantes, en vez de volver más democrática la vida institucional ha tendido a que, de hecho, dicho estamento como colectividad pierda significativamente peso en la toma de las decisiones institucionales.

Se tiene, entonces, que la UNA es con respecto a su organización y funcionamiento interno una pequeña "república", donde "ciudadanos" son todos los individuos que tienen derecho a elegir a las autoridades en puestos de "elección popular". Sin duda por su génesis medieval, sea la UNA, la UCR, o la UNED, las diferentes universidades públicas costarricenses mantienen, en general, una resistente estructura jerárquica piramidal con su "príncipe" (el rector), sus "señores feudales" (los decanos) y sus "capitanes generales" (los directores); pero que con la revolución liberal burguesa se ha transformado en un híbrido republicano presidencialista sobre el supuesto del individuo-ciudadano, en que los puestos de dirección se eligen y alternan por medio de elecciones "democráticas"; 3 pero manteniendo la estructura básica del ejercicio del poder. Se tiene, pues, una estructura organizativa vertical con cargos de autoridad en distintos planos y relaciones con el poder y responsabilidad de gestionar y dirigir la Universidad, siendo las personas que ocupan por periodos establecidos esos sitiales escogidos en el seno de la comunidad universitaria mediante elecciones. Así, en la poliarquía institucional la potestad
2. El estudio y discusión sobre "democracia" en general y sobre "poliarquía" en particular es enormemente amplio como vasta la literatura disponible. Solo como ilustración de puntos de referencia obligada en la literatura en español se

puede pensar en el texto de Norberto Bobbio, El futuro de la democracia (México, Fondo de Cultura Económica, 1994).

Como también el libro de

Robert Dahl, Poliarquía (México, Tecnos, 1971). Igualmente, de Roberto Dahl, La democracia, una guía para los ciudadanos (Madrid, Taurus, 1999). O la obra de Crawford B. MacPherson, La democracia liberal y su época (Madrid, Alianza Editorial, 2003)

3. Esta idea de la "república universitaria" es muy latinoamericana. En general, vale tener presente que en las universidades europeas, vale tener presente, se mantiene el "claustro de profesores" como la máxima (y por cierto poco democrática) autoridad académica de la institución. 
4. La participación estudiantil en el gobierno universitario, así como la lucha por la autonomía universitaria, es muy propia de una tradición latinoamericana. Se trata sobre todo de una conquista y baluarte de la lucha libertaria del movimiento estudiantil que arranca en 1918 con la huelga de la Federación Universitaria de Córdoba, Argentina, y cuyo legado histórico se plasma en su famoso Manifiesto Liminar.

5. Con la categoría de "universidad necesaria", se recupera una tradición crítica sobre el papel que las universidades deberían tener en los procesos de lucha popular por superar el subdesarrollo y la dependencia en los países latinoamericanos. Tal vez el pensador brasileño Darcy Ribeiro es la figura más conocida de esta línea de pensamiento. de elegir a las autoridades universitarias, así como aprobar las mismas normas constituyentes y operativas del quehacer diario, está (en el plano de la formalidad positiva) en manos de estos ciudadanos. Como individuos no son todos iguales en cuanto ciudadanos, ya que por definición se trata de una comunidad académica. Son los académicos, finalmente, los responsables por el ser y el quehacer sustantivo de la república en cuanto casa de estudios superiores que es; a esa responsabilidad debe corresponder, de igual forma en última instancia, el poder de decidir; en otras palabras, la república académica debe funcionar, debe ser gobernada por los académicos, aun con la eventual y absoluta oposición conjunta de estudiantes y trabajadores administrativos. Se mantiene, en definitiva, la figura del "claustro de profesores", clásico eje del poder en la universidad medieval. Tenemos, entonces, como una variante posible, que el "pueblo universitario" de la UNA, que la tradición liberal burguesa hace titular del poder y empodera en el ciudadano elector, lo conforman en esta casa de estudios tres estamentos diferenciados por su peso relativo en la potestad de elegir: académicos, que tienen un 60 por ciento del poder de elección, estudiantes con un 25 por ciento ${ }^{4}$ y administrativos con un 15 por ciento; recayendo, por supuesto, en académicos los fundamentales cargos de autoridad. Se trata, por tanto, que los académicos con ese 60 por ciento deben estar en capacidad, solos, si es del caso, de hacer funcionar la Institución. No obstante, subyace siempre el supuesto del individuo racional y libre como ladrillo base de toda la construcción institucional.

Empero, se debe tener claro, que la poliarquía trata de mecanismos formales que solo son una dimensión del ejercicio poder; y la presente reflexión se centra precisamente en este ámbito de lo procedimental, cuyo interés es explorar la especificidad en los cambios (o la ausencia de estos) que se han venido produciendo con la entrada en vigor del pobre (por carencial e intrascendente) nuevo Estatuto Orgánico. Miseria de la norma constituyente porque no existe "la democracia" tal cual, sino procesos de democratización que deberían dar cuenta de empoderamiento ciudadano como potenciación de la condición humana, como resalta Armando Bartra. Esto es claramente una profunda carencia del nuevo Estatuto dado que, en el seno de la comunidad universitaria de la UNA, su organización burocrática apoca al trabajador universitario en su potencia y responsabilidad y en ese sentido nada mejora el ahora vigente Estatuto Orgánico. El individuo-ciudadano, indudablemente, es un elemento libertario; sin embargo, en su abstracción procedimental se torna un espejismo alienante al perder conciencia de su condición social en tanto confrontación o solidaridad con los otros en el ejercicio asimétrico del poder. En la sensibilidad que impone la Modernidad, solamente nos reconocemos como individuos aun cuando, como en el caso de la UNA —todavía más cuando se la apropia como Universidad Necesaria ${ }^{5}$ - la Institución es, para usar una expresión común, mucho más que la suma de las partes y el individuo solo se potencia en cuanto tal en la colectividad que constituye el todo y que debería concretarse en su misión histórica, en una dialéctica del sujeto social, constituyéndose como tal en la apropiación de su propio devenir. Como Universidad Necesaria, se recupera una tradición latinoamericana de, por una parte, entender que las universidades son producciones históricas y, 
por otra parte, asumir un compromiso político al ligar ese devenir académico con las luchas populares de estos pueblos. Tal es el contexto de significación de la conocida cita del rector/fundador de la UNA, Presbítero Benjamín Núñez Vargas, que encabeza el nuevo Estatuto Orgánico:

La Universidad Necesaria es un ente vivo. Está enclavada en la historia como respuesta a las necesidades del desarrollo de un pueblo, y se va haciendo con la historia de ese pueblo. La Universidad Necesaria vive con y por el hombre costarricense en su larga e interminable jornada de infinita autorrealización. Ya lo dijo Omar Dengo: "Y es que una civilización nueva necesita un hombre nuevo y una nueva escuela" (Universidad Nacional 2015a).

Lamentablemente, el nuevo Estatuto Orgánico dice muy poco de procesos democratizadores de desconcentración o descentralización que empoderen a cada trabajador de la Institución como sujeto del devenir de la UNA.

\section{Del voto universal}

¿En qué fundamentos se sostiene el prototipo de liberalismo procedimental? La formulación procedimental, incluido el "liberalismo igualitario" y las demás variantes teóricas de raíz kantiana que concuerdan en sostener la primacía absoluta de los derechos individuales, asume dos elementos centrales: por una parte, la dignidad de la persona y la autonomía de la voluntad, que nacen de la universal racionalidad de los individuos; por la otra, la teoría de un contrato social originario establecido precisamente entre individuos racionales que son libres e iguales (Díaz-Polanco 2006, 49-50).

Esta pequeña república universitaria que es la UNA es, pues, heredera del liberalismo procedimental; pero por su propia naturaleza letrada (y ojala algún día ilustrada) no puede ni debe esconder las diferencias sustantivas entre los individuos en el ámbito de la comunidad universitaria: en su especificidad y 
6. La "democracia burguesa" transformada en formal mecanismo electoral termina escondiendo las estructurales y necesarias diferencias y desigualdades sociales funcionales al proceso de acumulación de capital. En el capitalismo, la asimetría real en el ejercicio del poder se oculta detrás de una igualdad formal de los individuos en tanto ciudadanos electores. Esto sin considerar los burdos mecanismos de exclusión tales como "Todos son ciudadanos, menos los negros", "Todos pueden votar, menos las mujeres", etc.

7. Obsérvese que la condición de estudiante como la condición de académico tiene directa y sustancial relación por definición con las tareas sustantivas de la Universidad (docencia, investigación y extensión), pero no así el administrativo. Por lo anterior, en muchas universidades se concluye que el estamento administrativo de la ciudadanía, ya que no tiene por qué participar en el gobierno de la institución pues sus intereses gremiales responderían a una lógica distinta del plano, en general, académico.

8. El designado "representante" en la votación primaria y universal al interior del propio estamento, se supondría que llevará la "voluntad mayoritaria" manifiesta al interior de su colectivo la hora de participar en el segundo momento de la elección general que reúne a toda la comunidad universitaria. Pero el supuesto de "expresión de la voluntad de la mayoría" generalmente no se cumple en la "democracia representativa". sustantividad esencial, entre el estudiante y el maestro. ${ }^{6}$ Es una diferenciación social que en ningún momento niega la autonomía de la voluntad y la dignidad de cada individuo como ser racional; no obstante, necesariamente reivindica papeles distintos en momentos diferentes de la ontogénesis. Así, la división de la comunidad universitaria en tres estamentos supone que cada uno de ellos tiene sus propios y particulares intereses dentro de la Institución y que, en consecuencia, se comportarán como sujeto colectivo tanto en los procesos electorales para elegir a las autoridades universitarias, como en función de la promoción y defensa cotidiana de sus específicas necesidades y aspiraciones. ${ }^{7}$ de la Universidad Nacional, para esta reflexión, en las consecuencias de la puesta en operación para todos del voto universal.

Se entiende en esta situación contradictoria entre la primacía del individuo, supuestamente recuperada mediante el voto universal, y el deterioro de hecho que ha supuesto esta universalización en lo que se refiere al poder real del estudiantado como estamento, precisamente la crítica que hace Héctor Díaz-Polanco a los supuesto políticos e ideológicos que subyacen a la concepción burguesa de "un contrato social originario establecido precisamente entre individuos racionales que son libres e iguales." Un contrato original que, en esta supuesta primacía del individuo, esconde el hecho de las divisiones y conformaciones de colectividades (estamentos, clases sociales, etc.) con intereses propios y hasta contradictorios en el interior del todo social.

En el caso de los estudiantes y trabajadores administrativos, en la Universidad Nacional hasta hace poco lo que predominaba era una votación indirecta delegada en dos pasos: en un primer momento por medio del voto universal al interior del estamento se elegían representantes quienes, en un segundo momento, ejercían su voto junto a los otros estamentos para completar formalmente el todo del acto electoral. ${ }^{8}$ En los académicos ha primado el voto universal y directo, aunque también se tiene formas de segundo grado como la "Asamblea de Representantes".

Ahora bien, en los últimos años se ha dado una justa (pero no necesariamente inteligente) lucha estudiantil por el logro del voto universal: que todos y cada uno de las y los estudiantes ejerzan directamente su derecho al voto en las elecciones de las autoridades universitarias. Como material para la recuperación histórica de esta lucha, se puede leer el texto "Movimiento Estudiantil de la UNA: Hora Cero" de Lorenzo Ramírez Cardoza. A manera de ilustración de este texto se puede citar:

Vale la pena pues un recuento histórico de lo sucedido. Podemos registrar al menos dos momentos fundamentales de la construcción del VUE: su primer momento, se construyó a través de la realización de un plebiscito encabezado por un grupo de estudiantes que se autodenominó Poder Estudiantil Popular (PEP), antes FEUNA-NO- 
ALINEADA, el 16 de marzo del 2009, al que fueron convocados todos y todas las estudiantes. En este se decidió sobre la interpretación del artículo 54 del entonces vigente Estatuto Orgánico de la FEUNA (EOFEUNA), acerca de la composición de la Asamblea Universitaria, para que se comprendiera por "representación estudiantil" en el proceso electoral de rectoría del 2010 a todos (as) y cada una de los (as) estudiantes que conforman la población estudiantil. Aun cuando en el plebiscito los votantes apoyaron por mayoría la propuesta, el Tribunal Electoral Universitario (TEUNA) impidió su ejecución señalando que lo aprobado por los estudiantes no podía ser acatado, pues la palabra "representación" solo podía interpretarse de manera literal, impidiendo que el VUE pudiera efectuarse para las elecciones del 2010. Para el TEUNA el producto de nuestro trabajo, el EOFEUNA, es algo autónomo a nosotros mismos, algo ajeno que se impone a nuestra voluntad. Es desde luego un criterio fetichista, el resultado de la producción humana aparece como un producto ajeno a esta que le domina, que en aquel entonces no se tuvo capacidad organizativa para vencer (2015).

Una reivindicación clásica del individualismo liberal, pero no necesariamente inteligente desde la perspectiva de ejercer de manera eficaz el 25 por ciento del peso relativo de ese estamento: no es lo mismo que todos los académicos y administrativos ciudadanos voten (incluyendo que son trabajadores de la Institución y si no votan les rebajan un día de su salario), que todos los estudiantes voten. En este sentido, si se parte del voto universal y directo de todos los ciudadanos, resulta, consecuentemente, que el peso electoral de cada individuo varía según el estamento de pertenencia y la población total del mismo: a manera de ilustración, si se tiene una población de 10.000 estudiantes, cada estudiante que vote en una elección de rectoría, por ejemplo, representará 0,0025 del ciento por ciento posible del resultado de esos comicios; mientras que si se tiene $\mathbf{1 . 0 0 0}$ académicos para el mismo proceso electoral, cada uno de ellos es portador de un 0,060 del ciento por ciento. Para que los estudiantes hagan "uso" de la totalidad de su cuota de 25 por ciento se requiere, en principio, que la totalidad de los estudiantes voten. Además 
9. Los datos sobre resultados electorales de la elección de Rectoría 2005. 2010 y 2015 nos fueron facilitados por el Tribunal Electoral de la Universidad Nacional (TEUNA). A estos compañeros en la persona de su presidente, don Oscar Salas Huertas, nuestro reconocimiento y agradecimiento. de las diferencias sociales del individuo que conforma el estamento, entre mayor sea el número de personas de una colectividad electoral mayor el número de quienes por las más diversas contingencias no ejercerán el voto.

Debe, por lo tanto y además para señalar asimetrías, tenerse presente que el uso de la totalidad de la cuota del 25 por ciento asignada a los estudiantes pasa, pues, porque vote la totalidad de los estudiantes empadronados y lo mismo pasa con los trabajadores administrativos, pero no así con los académicos, y esto último por el mecanismo de cuantificación de los resultados de una elección que se denomina "votos ponderados".

Tabla 1. Padrón de las elecciones de rectoría de los años 2005, 2010 y $2015^{9}$

\begin{tabular}{lcccccc}
\hline \multicolumn{1}{c}{ Año } & \multicolumn{2}{c}{2005} & \multicolumn{2}{c}{2010} & \multicolumn{2}{c}{$\mathbf{2 0 1 5}$} \\
& Abs. & $\%$ & Abs. & $\%$ & Abs. & $\%$ \\
\hline Académicos & 577 & 37,3 & 590 & 33,2 & 648 & 3,4 \\
Estudiantes & 240 & 15,6 & 246 & 13,8 & 17.540 & 90.6 \\
Administrativos & 728 & 47,1 & 942 & 53,0 & 1.163 & 6,0 \\
Total & $\mathbf{1 . 5 4 5}$ & & $\mathbf{1 . 7 7 8}$ & & $\mathbf{1 9 . 3 5 1}$ & \\
\hline
\end{tabular}

Fuente: Elaboración propia con base en datos suministrados por TEUNA.

En la tabla 1, el "Abs." dice de la cantidad de personas que conforman el estamento y "\%" dice del peso relativo de ese número de personas en el total del padrón electoral. Así, en esta tabla se muestran como el número de estudiantes con derecho a votar, producto de la reivindicación del voto universal, pasa de 246 en las elecciones de rectoría de 2010, que eran apenas un 15.6 por ciento de los individuos empadronados y "representantes" del total de estudiantado, a 17.540 en el año de 2015, un 90,6 del total de personas empadronadas cuando cada estudiante regular pudo expresar directamente su personal e individual voluntad. Esto es, en el 2010, 246 individuos representaban el 25 por ciento del peso relativo de los estudiantes y en la próxima elección, en el año 2015, ese 25 por ciento se tuvo que dividir entre 17.540 estudiantes. El total de lectores pasa de 1.778 en el 2010 a 19.351 en las últimas elecciones, pero el peso relativo de 60, 25 y 15 por ciento entre los estamentos no varía. Lo que va a variar es el uso o capacidad para hacer efectivo ese peso relativo de cada estamento, ya que, con el voto universal de los estudiantes, ese estamento - como era previsible, y de ahí la calificación que hacemos de "poco inteligente" la lucha por esta reivindicación- perdió poder de elegir, reduciéndose esa capacidad casi en una cuarta parte. La lucha por el voto universal debe (debió) hacerse acompañando la reivindicación sustantiva de mecanismos operativos que posibiliten su ejercicio real.

En cuanto al abstencionismo por parte de los estudiantes y con ello el uso de su cuota de poder, como resultado de este cambio de una elección de segundo grado por medio de representantes, como sucedía en los años 2005 y 2010, a unos comicios de voto universal, donde todos los estudiantes podían 
decidir directamente en el proceso electoral de 2015, se muestra en la siguiente tabla:

Tabla 2. Porcentaje de votos emitidos en las elecciones de rectoría de los años 2005, 2010 y 2015

\begin{tabular}{lccccccccc}
\hline \multicolumn{1}{c}{ Año } & \multicolumn{3}{c}{$\mathbf{2 0 0 5}$} & \multicolumn{3}{c}{$\mathbf{2 0 1 0}$} & \multicolumn{3}{c}{$\mathbf{2 0 1 5}$} \\
& inscritos & votaron & $\%$ & inscritos & votaron & $\%$ & inscritos & votaron & $\%$ \\
\hline Académicos & 577 & 534 & 92,55 & 590 & 563 & 95,42 & 648 & 578 & 89,20 \\
Estudiantes & 240 & 222 & 92,50 & 246 & 225 & 91,46 & 17540 & 4454 & 25,39 \\
Administrativos & 728 & 700 & 96,15 & 942 & 892 & 94,69 & 1163 & 1081 & 92,95 \\
\hline
\end{tabular}

Fuente: Elaboración propia con base en datos suministrados por TEUNA.

El "\%" es el porcentaje de los estudiantes que pudiendo votar así lo hicieron. Los electores estudiantiles (representantes) participaron en el 2005 en un 92,50 por ciento ( 7,50 por ciento de abstencionismo), en las elecciones siguientes el abstencionismo estudiantil subió de manera leve a 8,54 por ciento. Pero con la introducción del voto universal, en el 2015, la abstención entre los estudiantes subió a 74,61 por ciento. Abstención que se traduce, evidentemente, en una pérdida de poder electoral de este estamento como un todo, como sujeto colectivo, frente a los otros colectivos de ciudadanos (trabajadores académicos y administrativos). Así, la consecuencia del voto universal, como era de esperarse, fue una dramática caída en el peso relativo del estudiantado en la elección de las autoridades universitarias. En la siguiente tabla se cuantifica esta caída del poder de elegir por parte de los y las estudiantes:

Tabla 3. Voto ponderado por estamento en las elecciones de rectoría de los años 2005, 2010 y 2015

\begin{tabular}{lccccccccc}
\hline \multicolumn{1}{c}{ Año } & \multicolumn{3}{c}{$\mathbf{2 0 0 5}$} & \multicolumn{3}{c}{$\mathbf{2 0 1 0}$} & \multicolumn{3}{c}{$\mathbf{2 0 1 5}$} \\
& electores & $\%$ & peso & electores & $\%$ & peso & electores & $\%$ & peso \\
\hline Académicos & 534 & 92,55 & 534 & 563 & 95,42 & 563 & 578 & 89,20 & 578 \\
Estudiantes & 222 & 92,50 & 222,00 & 225 & 91,46 & 225,00 & 4.454 & 25,39 & 68,56 \\
Administrativos & 700 & 96,15 & 138,70 & 892 & 94,69 & 139,67 & 1.081 & 92,95 & 150,58 \\
Total & $\mathbf{1 . 4 5 6}$ & $\mathbf{8 9 4 , 7 0}$ & $\mathbf{1 . 6 8 0}$ & & $\mathbf{9 2 7 , 6 7}$ & $\mathbf{6 . 1 1 3}$ & & $\mathbf{7 9 7 , 1 4}$ \\
\hline
\end{tabular}

Fuente: Elaboración propia con base en datos suministrados por TEUNA.

En esta tabla 3, "electores" son las personas que emitieron su voto, el "\%" se refiere al porcentaje de esos individuos que votaron en relación con el total de votantes inscritos en cada estamento, y el "peso" dice del número de "los votos ponderados" conseguidos por cada estamento del total de votos ponderados resultado de los comicios: 894,70 votos ponderados en el año 2005, 927,67 en el 2010 en la última elección de rectoría 797,14. Cálculo que se basa en considerar que cada académico que votó es un "voto ponderado", de 
ahí que, como puede observarse en la tabla 3, el número de académicos electores es igual al número de "votos ponderados" para ese estamento.

Ahora bien, el "voto ponderado" es el producto de la definición de un cálculo aritmético establecido en el Reglamento del Tribunal Electoral Universitario (TEUNA). Un cálculo que, partiendo de los académicos con derecho a voto como base, determina, en un primer paso o momento, el peso por votante (que puede ser delegado o directo) del correspondiente 25 y 15 por ciento de los estudiantes y administrativos respectivamente para establecer la "Asamblea Plebiscitaria Electoral". Asamblea que se conforma según sea la autoridad que debe elegirse, por ejemplo, la rectoría o un decanato o una dirección de escuela. Véase como ilustración el Artículo 42 del Reglamento del TEUNA:

Artículo 42. Integración de la asamblea universitaria plebiscitaria electoral.

La Asamblea Universitaria Plebiscitaria Electoral definida en el artículo 24 del Estatuto Orgánico, con la excepción indicada en el artículo 42 bis de este reglamento, se integrará según el artículo 25 del Estatuto Orgánico, de la siguiente manera:

a) El personal académico en propiedad y el personal académico no propietario con al menos cinco años de tiempo servido en la Universidad Nacional, con nombramientos consecutivos, en una jornada a tiempo completo. En conjunto corresponden al sesenta por ciento de la integración de la Asamblea.

b) El personal administrativo en propiedad y el personal administrativo no propietario con al menos cinco años de tiempo servido en la Universidad Nacional, con nombramientos consecutivos, en una jornada a tiempo completo. En conjunto corresponden al quince por ciento de la integración de la Asamblea, mediante voto universal ponderado. Para determinar la equivalencia del $15 \%$ de la representación administrativa, se multiplica 15 por el resultado del inciso a) y el producto se divide entre 60 . 
c) La representación estudiantil correspondiente al veinticinco por ciento de la integración de la Asamblea, electa mediante el procedimiento establecido en el Estatuto de la FEUNA. Para determinar la equivalencia del $25 \%$ de la representación estudiantil, se multiplica 25 por el resultado del inciso a) y el producto se divide entre 60 .

Se suman los resultados de los incisos a), b) y c) y el resultado se denominará "TOTAL DE INTEGRANTES DE LA ASAMBLEA UNIVERSITARIA PLEBISCITARIA ELECTORAL".

Para ninguno de los estamentos (académico, administrativo o estudiantil) el voto individual podrá tener valor mayor a uno (2015b). En un segundo momento, usa el número de académicos que efectivamente votaron como base para calcular el resultado de la votación. Se trata de una definición que al tener como base a los académicos tanto para establecer el padrón (primer momento), como para calcular el resultado de la votación (segundo momento) ponderando el peso de estudiantes y administrativos que acudieron a votar tomando como base los académicos que igualmente votaron, termina favoreciendo a los académicos en su peso relativo con respecto a los otros dos estamentos. Debe observarse, reiterando, que precisamente el voto ponderado parte en los dos momentos del número de académicos: primero los académicos inscritos como base para establecer la relación entre número de votantes individuales estudiantiles y administrativos empadronados y el 25 y 15 por ciento del padrón que les corresponden respectivamente. En un segundo momento, del número de académicos que efectivamente votaron como bases para calcular el peso relativo de los estudiantes y trabajadores administrativos que también votaron, pero contrastándolos con los que debieron votar (por eso es que hablamos de que se castiga el abstencionismo de estudiantes y administrativos, pero no el de los académicos).

Así, pues, y sin entrar en mayores detalles de cómo se calcula estos "votos ponderados", en la tabla 4 se hace la estimación del peso relativo entre los tres sectores en el resultado final de los comicios considerando simplemente el "castigar" el abstencionismo porcentual directo. En otras palabras, si solo vota la mitad de los electores inscritos en cualquier estamento, entonces este abstencionismo conlleva a perder la mitad de su poder relativo de elegir. Se trata de un ejercicio que busca contrastar el "castigo" de abstencionismo entre estudiantes y administrativos que hace el "voto ponderado" utilizado por el TEUNA. ${ }^{10}$ Sencillamente y para resaltar los efectos del voto universal, se parte que, si diera un 100 por ciento de votación en los tres estamentos, el peso relativo en el poder de elegir entre ellos sería 60, 25 y 15 por ciento respectivamente. No obstante, si ningún administrativo votara, a manera de ilustra-

10. En la forma establecida para calcular los "votos ponderados", el abstencionismo en los académicos no solo no se castiga, sino que el aumento del abstencionismo entre los estudiantes y los administrativos termina favoreciendo el peso relativo de los académicos en la elección. 
ción, entonces el peso de elegir de los administrativos sería 0 , si la mitad de los administrativos votara, entonces el peso de elegir de este estamento sería 7,5 por ciento, etc.

Tabla 4. Peso relativo de elegir por estamento en las elecciones de rectoría de los años 2005, 2010 y 2015, tomando en consideración una relación directa con el abstencionismo

\begin{tabular}{lccccccccc}
\hline \multicolumn{1}{c}{ Año } & \multicolumn{3}{c}{2005} & \multicolumn{3}{c}{$\mathbf{2 0 1 0}$} & \multicolumn{3}{c}{$\mathbf{2 0 1 5}$} \\
& inscritos & $\%$ & peso\% & inscritos & $\%$ & peso\% & inscritos & $\%$ & peso\% \\
\hline Académicos & 577 & 92,55 & 55,53 & 563 & 95,42 & 57,25 & 648 & 89,20 & 53,52 \\
Estudiantes & 728 & 92,50 & 23,12 & 225 & 91,46 & 22,86 & 1.163 & 25,39 & 6,35 \\
Administrativos & 240 & 96,15 & 14,42 & 892 & 94,69 & 14,20 & 17.540 & 92,95 & 13,94 \\
\hline
\end{tabular}

Fuente: Elaboración propia con base en datos suministrados por TEUNA.

En esta tabla 4, "inscritos" es el total de personas con derecho a votar, el "\%" dice del porcentaje de esos individuos que votaron en relación con el total de votantes inscritos, y el "peso\%" es la "cantidad usada" del total del porcentaje que le corresponde al segmento (60, 25 y 15 por ciento respectivamente). Aquí lo que interesa resaltar es el hecho que los estudiantes de su derecho de elegir de un 25 por ciento, en el 2005 usaron 23,12 por ciento, 22,86 por ciento en el 2010 y solo aprovecharon un 6,35 por ciento en el 2015. Esta caída en la última elección de rectoría es, pues, el resultado de la reivindicación del voto universal.

Los efectos de "castigo" al abstencionismo en estudiantes y administrativos que conlleva la fórmula de cálculo del "voto ponderado" se pueden ver comparando este último con la participación efectiva de los electores de cada estamento, tal como se hace en la tabla 5. Aquí se le asigna a cada estamento el 60, 25 o 15 por ciento que le corresponde de un eventual resultado electoral si sus electores acuden en su totalidad a emitir el sufragio. $Y$ se va reduciendo ese 60, 25 o 15 por ciento según dejen de participar los individuos empadronados. A manera de ejemplo, si solo llega a votar la mitad de los académicos empadronados, entonces el peso relativo de ese estamento en el resultado final baja de un 60 a un 30 por ciento. Un ejercicio comparativo para resaltar los efectos del cálculo del "voto ponderado" en contraste con la participación electoral real de los ciudadanos.

En la tabla 5, "ponderado" es el resultado de la elección según el cálculo del voto ponderado; que necesariamente suma un 100 por ciento. "Directo" es el porcentaje de la cuota total posible para cada estamento en función del porcentaje de votos emitidos (se "castiga" el abstencionismo en cada estamento. De esta manera en el 2005 del 60 posible, por ejemplo, los académicos hicieron uso de un 55,53 por ciento de su cuota, pero con el cálculo de "voto ponderado" esa votación se convirtió en un 59,68 por ciento del 100 por ciento de resultado final. Sin embargo, para el 2015 porcentualmente menos académicos fueron a votar y solo hicieron uso de un 53,53 por ciento de su cuota, 
pero con el cálculo del voto ponderado, esa participación se convierte en un 72,50 de peso en el resultado final. Este efecto se debe al "castigo" que se les hace a los estudiantes por su baja participación: lo que el estudiantado "deja de usar" se reparte entre los otros dos estamentos. Debe tenerse presente que el 60 por ciento de la cuota de los académicos convertiría en el 100 por ciento del resultado final según el voto ponderado el caso que ningún estudiante y administrativo votara.

Tabla 5. Comparación entre el peso relativo según el cálculo de "voto ponderado" y el porcentaje directo en función del abstencionismo por estamento en las elecciones de rectoría de los años 2005, 2010 y 2015

\begin{tabular}{lcccccc}
\hline \multicolumn{1}{c}{ Año } & \multicolumn{2}{c}{2005} & \multicolumn{2}{c}{2010} & \multicolumn{2}{c}{2015} \\
& ponderado & directo & ponderado & directo & ponderado & directo \\
\hline Académicos & 59,68 & 55,53 & 60,68 & 57,25 & 72,50 & 53,52 \\
Estudiantes & 24,81 & 23,12 & 24,25 & 22,86 & 8,6 & 6,35 \\
Administrativos & 15,50 & 14,42 & 15,05 & 14,20 & 18,89 & 13,94 \\
Suma porcentual & $\mathbf{1 0 0 \%}$ & $\mathbf{9 3 , 0 7 \%}$ & $\mathbf{1 0 0 \%}$ & $\mathbf{9 4 , 3 1 \%}$ & $\mathbf{1 0 0 \%}$ & $\mathbf{7 3 , 8 1 \%}$ \\
\hline
\end{tabular}

Fuente: Elaboración propia con base en datos suministrados por TEUNA.

No obstante, lo que interesa aquí es resaltar cómo los estudiantes tuvieron una tremenda caída en su poder de elegir con la introducción del voto universal; de ahí que inicialmente califiquemos esta reivindicación, sin ninguna otra mediación, como de no inteligente (si se quiere, política - electoralmente poco inteligente, por más justa que sea). Lamentablemente esta pérdida del poder de elegir de los estudiantes con la introducción del voto universal es una tendencia generalizada, tal como puede constatarse por los resultados obtenidos en recientes procesos electorales como los que han tenido lugar en la Escuela de Música, en la Escuela de Economía, en la Escuela de Ciencias del Movimiento Humano y Calidad de Vida. La consecuencia negativa de la introducción del voto universal para el poder de elegir de los estudiantes es evidente: han perdido poder político - electoral al interior de la pequeña república universitaria y con ello poder en la lucha por sus propios intereses y reivindicaciones como estamento.

\section{Una propuesta alternativa}

Cuanto más democrático sea el régimen político, tanto más claro será para los obreros que la raíz del mal es el capitalismo y no la falta de derechos. Cuanto más amplia sea la igualdad nacional (que no es completa sin la liber- 
tad de separación) tanto más claro será para los obreros de la nación oprimida que el quid de la cuestión está en el capitalismo y no en la falta de derechos. Y así sucesivamente (Lenin 1985, 133).

"La" democracia no existe, excepto como concepto-valor en formas discursivas o discursos. A este respecto señala el profesor Helio Gallardo (s.f.):

Si "la" democracia no existe sino al interior de un discurso determinado, ¿qué existe entonces en la existencia diaria y material y no puramente como discurso? Lo que existe son instituciones democráticas que condensan y expresan, mejor o peor, lógicas democráticas. Estas instituciones resultan del juego de diversas fuerzas sociales en el marco de un Estado de derecho (o por su constitución si es que este dispositivo no existe), o sea de una convivencia regulada y sancionada por leyes de aplicación universal (general), y que funcionan de un modo tal que nadie pueda ser perseguido y hostilizado, excepto por la comisión o sospecha de comisión de algún delito. En este Estado, nadie, tampoco, es un ciudadano "por encima de toda sospecha". Lo que vale para los individuos vale asimismo para los sectores sociales. A este decantamiento de instituciones que funcionan de acuerdo a una lógica democrática las englobamos bajo la expresión o concepto "procesos de democratización". Los procesos de democratización son, obviamente, sociohistóricos y, entre otras diferencias en relación con "la" democracia, admiten perfeccionamiento, y también retrocesos, al interior de su propio despliegue. Es una discusión, en cambio, que puedan ser "mejorados" desde otros marcos, es decir mediante la incidencia de fuerzas sociales alternativas a las social y políticamente reinantes. 
Se trata, desde esta perspectiva que nos presenta el profesor Gallardo, de cuestionarse por la profundización o no de la participación democrática de los distintos estamentos a lo interno de la UNA a partir de los cambios procedimentales electorales que introdujo el nuevo Estatuto Orgánico. Ver la materialidad que hace real o no un determinado cambio formal en el ejercicio de un derecho. Se trata de hacer un ejercicio crítico desde "la izquierda" a la concepción liberal burguesa de "la democracia" que es de larga data. Vladimir I. Lenin, por ejemplo, es uno de los críticos más acérrimos de una "democracia formal" que lo que hace es esconder las contradicciones existentes en el seno de la sociedad. Pero un crítico que para nada deja de reconocer y hasta promover la conquista de derechos jurídicos, pero insistiendo en que el quid de la cuestión está en la materialidad o no de esos derechos que haga o no posible el ejercicio real de estas conquistas. No existe "la democracia" sino procesos de democratización o no de la vida política al interior de una sociedad, comunidad o institución.

Desde este horizonte, en esta pequeña república universitaria de la UNA, lo que existen son procesos más democráticos que potencien o menos democráticos (hasta meramente arbitrarios) que castren el aporte de cada uno (académico, estudiante o administrativo) al cumplimiento de la misión histórica institucional en función con sus valores, principios y fines, así como a la satisfacción de sus necesidades particulares. Los mecanismos formales para la elección de las autoridades universitarias ciertamente pueden ser más o menos democráticos, y siempre a este respecto debemos estar atentos en distinguir entre la formalidad de un derecho y su real ejercicio. Como reitera Lenin, la sociedad capitalista en oposición al antiguo régimen será muy generosa en derechos positivos individuales (la formalidad del derecho) al mismo tiempo que profundiza la dominación y explotación de las grandes mayorías (la realidad del ejercicio del poder), contradicción que se oculta en una igualdad formal de todos y todas en tanto ciudadanos. En este sentido, la división de nuestra comunidad universitaria en tres estamentos supone, tal como se ha dicho arriba, que cada uno de ellos tiene sus propios y particulares intereses al interior de la Institución, y que en consecuencia se comportarán como sujeto colectivo tanto en los procesos electorales para elegir las autoridades universitarias, como en función de la promoción y defensa cotidiana de sus específicas necesidades y aspiraciones. Por lo que la poliarquía institucional será más o menos democrática en tanto potencie o no la capacidad de cada estamento de intervenir eficazmente en la vida universitaria, siendo desde esta perspectiva claro que la introducción del voto universal se ha vuelto, hasta ahora, contraproducente a los intereses del estudiantado.

Se ha visto cómo la puesta en operación del voto universal trajo una abrupta caída del poder de los estudiantes. Formalmente cuentan con una cuota del 25 por ciento en el poder de elegir las autoridades universitarias, pero el voto universal redujo de hecho esa cuota a un 8,6 por ciento del voto ponderado en la elección del actual Rector: solo votaron un 25,39 por ciento de los estudiantes empadronados (una cuarta parte), con un uso de su cuota electoral de solo el 6,35 por ciento en vez de un 25 por ciento si todos los y las estu- 
diantes hubieran sufragado. Pero esto pasa por desconocer las condiciones reales de la eventual participación estudiantil en contraste con la de académicos y administrativos. Se está al frente de dos estamentos con situaciones individuales muy disímiles. En estos dos últimos estamentos se está al frente, por ejemplo, de trabajadores universitarios que están obligados a votar (a quien no vote se le castiga con reducirle una día de salario), que numéricamente son mucho menos que los estudiantes con todas las contingencias personales que pueden impedir que uno llegue a votar, que hay estudiantes que lo que llevan al momento de la elección es un único curso y en un día distinto de la votación y que ir a la Universidad supone un gasto que muchas veces no pueden ni siquiera cubrir, etc. Lo justo de pensar en el voto universal que haga de cada individuo la expresión directa de una voluntad, pierde su contenido democratizador cuando no toma en cuenta una realidad operativa negativa obstáculo operativo real para hacerla efectiva.

Es por estas razones que en la Propuesta Democrática - Alternativa Para Un Nuevo Estatuto Orgánico, ponencia presentada al IV Congreso Universitario, se hacía, por una parte, una propuesta para una redefinición más inclusiva de la ciudadanía universitaria al incorporar a los trabajadores interinos y, por otro lado, redefinir el mecanismo electoral que, incorporando el voto universal, fuera más democrático al evitar que diferencias individuales entre los electores de un estamento diera al traste con el peso relativo consensuado en la distribución del poder de elegir asignado para cada colectivo. Este planteamiento alternativo se justificaba de la siguiente manera:

La Propuesta Oficialista habla de una ciudadanía para el caso de los interinos a partir de los cinco años de tener una relación laboral con la Universidad. Aquí se propone que sea a partir de los dos años. Por otra parte, se establece el voto universal como la forma idónea del ejercicio de la ciudadanía, pero, eso sí, se requiere un mínimo de participación para que se valide la participación sectorial: un mínimo de participación electoral por parte de los académicos del sesenta por ciento, un cuarenta por ciento para los administrativos y un veinte por ciento en el caso de los estudiantes. Así, por ejemplo, si en una elección de Rector o Rectora participan menos de un veinte por ciento de los estudiantes, entonces no contará el voto estudiantil, por encima del veinte de estudiantes que hayan votado entonces, con su porcentual distribución según candidatos y votos nulos, el voto estudiantil valdrá un 
veinticinco por ciento. De igual forma para académicos y administrativos. Esto hace, otra ilustración, que con solo que dos tercios de los académicos voten (cuarenta por ciento de representación), y no vota ningún estudiante ni ningún administrativo, la elección es válida ya que un cuarenta por ciento de la representación total se ha hecho efectiva; faltando aún el requisito que un candidato o candidata debe obtener al menos un cuarenta por ciento de la representación para quedar electa, por lo que, en este ejemplo, para que un candidato quede electo deberá obtener el cien por ciento del voto del sector académico emitido (Cruz, Guardado, Horta, Páez y Vargas 2013).

El voto universal debía, entonces, ser acompañado con otro mecanismo para calcular el resultado final de una elección que mantuviera la proporcionalidad entre los tres estamentos $(60,25$ y 15 por ciento entre académicos, estudiantes y administrativos), evitando que el ejercicio real del sufragio desvirtuara las cuotas formales establecidas. Para ello estaban los artículos 5 y 6 de la Propuesta Democrática - Alternativa:

Artículo 5. Ciudadanía

La Universidad Nacional es una comunidad política conformada por tres sectores de personas: académicos, estudiantes y administrativos, ejerciendo toda una democracia participativa directa mediante el voto universal al interior de su respectivo grupo ${ }^{11}$

Artículo 25. Integración de la Asamblea Universitaria

La Asamblea Universitaria está integrada por:

a. El personal académico en propiedad y el personal académico no propietario con al menos cinco años consecuti-

11. En cada unidad académica, se constituye una asamblea de académicos, una de administrativos y una de estudiantes, las cuales eligen por medio de voto universal a sus representantes sectoriales para las autoridades colectivas según corresponda.

Igualmente, en la Universidad, como totalidad, es en el seno de una asamblea universitaria de estudiantes y una asamblea universitaria de administrativos (proceso electoral universal), que se eligen los representantes estudiantiles o administrativos en las instancias de dirección institucional. 
vos de laborar para la Institución en una jornada de tiempo completo. En conjunto corresponden al sesenta por ciento de la integración de la Asamblea.

b. El personal administrativo en propiedad y el personal administrativo no propietario con al menos cinco años consecutivos de laborar para la Institución en una jornada de tiempo completo. En conjunto corresponden al quince por ciento de la integración de la Asamblea, mediante voto universal ponderado.

c. La representación estudiantil correspondiente al veinticinco por ciento de la integración de la Asamblea, electa mediante el procedimiento establecido en el Estatuto de la FEUNA. (Universidad Nacional 2015a, 20-21).

Las diferencias básicas para que un trabajador interino obtuviera la ciudadanía entre las dos propuestas se dan en términos de años de laborar y tiempo de la jornada para la cual se trabaja para la UNA. En la Propuesta Democrática - Alternativa se planteó dos años de trabajar y al menos medio tiempo de jornada. Con la Propuesta Oficialista quedaron los requisitos en cinco años y tiempo completo. ¿Por qué cinco y no dos años de laborar y por qué tiempo completo y no medio tiempo de jornada? En realidad, no hay argumentos formales para que un trabajador con un contrato de interino sea también ciudadano desde el inicio de su labor en nuestra pequeña república universitaria. Aunque, es claro, sí hay razones de poder que no se explicitan como tales: el trabajador interino está en una situación de vulnerabilidad que puede ser aprovechada por otro.

En todo caso, vale hacer algunas preguntas: ¿por qué una persona que habiendo nunca trabajado para la Universidad, pero que por medio de un concurso externo gana en propiedad una plaza como académico o administrativo es de inmediato un ciudadano universitario, mientras que un trabajador con contrato como interino lleva dos, cinco o más años de laborar para la Universidad no tiene ciudadanía? ¿Por qué exigir tiempo completo cuando tenemos trabajadores propietarios de un cuarto de tiempo que son, por lo tanto, ciudadanos y votan? ¿Por qué, pues, un trabajador propietario de un cuarto de tiempo es ciudadano y un trabajador interino de tiempo completo no lo es? Se debe pensar también, sobre este aspecto de la jornada laboral, que las necesidades de jornadas completas o parciales varían de una Escuela a otra: distinguir entre la Escuela de Música, como ilustración, donde se pueden necesitar muchos profesores por los diversos instrumentos que se enseñan, 
pero a tiempo parcial por el pequeño número de estudiantes por instrumento que se tienen, con respeto a la Escuela de Sociología, siempre a manera de ilustración, donde lo recomendable posiblemente sea un cuerpo profesores de tiempo completo. Habría que hacer el estudio; sin embargo, es muy probable que haya significativas diferencias de necesidades en cuanto a las jornadas de contratación de sus trabajadores entre las distintas escuelas de la Universidad, lo que podría generar significativas asimetrías de poder. Pero el hecho es que con el nuevo Estatuto Orgánico se estableció jornada de tiempo completo y un mínimo de cinco años de laborar en la UNA para que un trabajador interino adquiera la ciudadanía.

Tabla 6. Número de trabajadores académicos interinos según antigüedad - nómina del mes de mayo del 2005, 2010 y 2015 -

\begin{tabular}{cccccc}
\hline Año & $\geq \mathbf{2}$ años $<\mathbf{5}$ años & \multicolumn{2}{c}{$\geq \mathbf{5}$ años } & Total \\
& Abs. & $\%$ & Abs. & $\%$ & \\
\hline 2005 & 25 & 3,0 & 6 & 0,7 & $\mathbf{8 4 2}$ \\
2010 & 67 & 5,6 & 26 & 2,2 & $\mathbf{1 1 9 2}$ \\
2015 & 167 & 13,9 & 102 & 8,5 & $\mathbf{1 2 0 0}$ \\
\hline
\end{tabular}

Fuente: Elaboración propia con base en datos suministrados por TEUNA.

En la tabla 6, donde "Abs." dice de número de trabajadores que cumplen la condición y "\%" refiere al peso porcentual de ese número con respecto al total de académicos interinos para ese año, muestra como el criterio de antigüedad es claramente excluyente en función de democratizar la condición y participación ciudadana entre los trabajadores académicos interinos. Los cinco años de laborar continuamente aprobados en el IV Congreso Universitario para dar la ciudadanía, únicamente favorecen a 8,5 por ciento de ese universo para el 2015. Si solo se pidieran 2 años de laborar para la Universidad, 22,5 por ciento de los académicos interinos cumplirían la condición. Pero aún hay que cruzar esta condición, antigüedad, con la exigida jornada de tiempo completo. Se trata, en todo caso, de analizar si las nuevas condiciones para incorporar a los trabajadores interinos a la ciudadanía son significativamente democratizadoras o no.

Tabla 7. Número de trabajadores administrativos interinos según antigüedad - nómina del mes de mayo del 2005, 2010 y 2015 -

\begin{tabular}{rlcccc}
\hline \multirow{2}{*}{ Año } & \multicolumn{2}{c}{$\mathbf{2}$ años $<\mathbf{5}$ años } & \multicolumn{2}{c}{$\geq \mathbf{5}$ años } & \multirow{2}{*}{ Total } \\
& Abs. & $\%$ & Abs. & $\%$ & \\
\hline 2005 & 138 & 25,5 & 31 & 5,7 & 542 \\
2010 & 211 & 34,6 & 127 & 20,3 & 610 \\
2015 & 128 & 27,5 & 190 & 40,9 & 465 \\
\hline
\end{tabular}

Fuente: Elaboración propia con base en datos suministrados por TEUNA. 
En el caso de los trabajadores administrativos interinos, el criterio de antigüedad es significativamente menos excluyente en comparación con los académicos. Para el 2015 habría 40,9 por ciento de individuos habilitados en lo que se refiere a este requisito. Pero si se reduce la exigencia a dos años, 68,4 por ciento de los interinos cumplirían. En ambos casos, académicos y propietarios, exigir solamente dos años de relación laboral es, reveladoramente, una medida más democratizadora.

Nótese ahora lo que refiere a la exigencia de jornada de trabajo para obtener o no la ciudadanía. El oficialismo impuso su exigencia de que "el personal académico no propietario con al menos cinco años consecutivos de laborar para la Institución en una jornada de tiempo completo" podía aspirar a la ciudadanía.

Tabla 8. Número de trabajadores académicos interinos según jornada - nómina del mes de mayo del 2005, 2010 y 2015

\begin{tabular}{cccccccc}
\hline Año & $<1 / 2 \mathbf{T}$ & $\%$ & $\geq 1 / 2<\mathbf{T}$ & $\mathbf{\%}$ & $\mathbf{1} \mathbf{1 T}$ & $\mathbf{\%}$ & Total \\
\hline 2005 & 453 & 53,9 & 256 & 30,4 & 132 & 15,7 & 841 \\
2010 & 424 & 36,3 & 377 & 32,3 & 367 & 31,4 & 1168 \\
2015 & 391 & 33,3 & 360 & 30,6 & 425 & 36,1 & 1176 \\
\hline
\end{tabular}

Fuente: Elaboración propia con base en datos suministrados por TEUNA.

En la tabla 8, se muestra que para el 2015, 36,1 por ciento (uno de cada tres) de los académicos interinos cumplen el requisito de jornada. Habría que verificar también si hay concentración de tiempos parciales en determinadas escuelas por condiciones específicas (la Escuela de Música, como ya se dijo, podría ser un caso), con lo que se estaría favoreciendo a unas unidades académicas en detrimento de otras. Una situación distinta la encontramos en el caso de los interinos. En el 2015, 90,0 por ciento cumplen con la disposición estatutaria.

Así, pues, para los académicos la exigencia de tiempo completo es poco democratizadora; aunque su afectación negativa no es superior en relación con los administrativos. Sin embargo, en todo caso, se debe tener presente que la obtención de la ciudadanía se podrá alcanzar cumpliendo simultáneamente el requisito de tiempo completo y cinco años de laborar para la Universidad.

\section{A manera de una conclusión propositiva}

La crítica social del principio de agencia no se limita a señalar la falsedad de su gestación (y uso actual) liberal, 
sino que busca constituirse en factor de la lucha social (y política) de quienes sufren discriminaciones sistémicas que les impiden comportarse como agentes, o sea como sujetos individuales y sociales capaces de producir experiencias de existencia humanas (o antihumanas) y de responsabilizarse por ellas. En breve, el eje de la crítica social del principio de agencia es su interés por las luchas que potencian para avanzar en la creación de condiciones sociohistóricas que posibilitan la libertad para todos los seres humanos (principio de agencia). Esta libertad resultará de diversas y prolongadas luchas de liberación (Gallardo 2008).

Lo conseguido en el IV Congreso Universitario en términos de ampliar la participación democrática en el seno de la comunidad universitaria es, como lo muestra la experiencia electoral posterior, muy pobre en el caso de los académicos, no relevante en lo que a los administrativos se refiere y un retroceso como sucedió con los estudiantes. En general, se está al frente de un retroceso desde la perspectiva de potenciar la capacidad creadora y liberadora en el seno la comunidad universitaria, siguiendo la visión crítica de Helio Gallardo. No obstante, la misma discusión es un logro muy positivo al imponerse institucionalmente una sensibilidad democratizadora que parte de reconocer en todos los individuos de la comunidad universitaria - sean académicos, estudiantes o administrativos - un ser humano racional de libre voluntad y, con ello, portador del principio de agencia, mediante el cual es capaz de imaginarse a sí mismo y luchar por construir su devenir histórico de acuerdo a esos anhelos y aspiraciones; como institución política, la comunidad universitaria se reconoce como responsable de su propia historia. La cuestión del poder está ahora en relación directa con el principio de agencia: el ser humano como agente de su propio devenir. Pero esta sensibilidad fue contradicha, refutada con los resultados obtenidos con las nuevas reglas electorales. A partir de dicha sensibilidad democratizadora, abrir la posibilidad de la ciudadanía para trabajadores interinos es, sin duda, un muy importante avance en el seno de la comunidad universitaria. Sin embargo, no se puede dejar de resaltar las limitaciones de este paso; hay que tener presente que para los trabajadores administrativos interinos, en el mejor de los escenarios, en el 2015 solo de 4 de cada diez podrían optar por la ciudadanía. Al mismo tiempo, en el mejor escenario para los académicos, únicamente 8,5 por ciento de ellos podría optar por la ciudadanía. Las normas aprobadas para la ciudadanía de los interinos son un avance, pero indudablemente insuficientes. La ciudadanía debe ampliarse formalmente y, sobre todo, profundizarse de manera real 
para potenciar el aporte de todos los trabajadores universitarios. Y en el caso de los estudiantes, reiteramos, ha habido un claro retroceso.

Los pobres resultados democratizadores de lo aprobado en el IV Congreso Universitario deben y pueden ser subsanados. Para ello, es posible tomar las siguientes medidas:

\section{El voto por internet}

Tomando en cuenta los costos del mecanismo electoral para la UNA, su facilidad para el votante y lo eficiente de su administración para el TEUNA, es necesario dejar en el pasado los comicios por medio de boletas impresas y pasar a que se puedan emitir el voto por medio de internet.

El voto por internet es, además, una forma de minimizar la pérdida del poder electoral de los estudiantes. Se trata no solo de abaratar y facilitar los procesos electorales, sino de favorecer sobre la participación efectiva de los estudiantes. El uso de internet para estos efectos vendrá a democratizar la vida política de la pequeña república universitaria. Sería un cambio en el mecanismo electoral que el TEUNA puede impulsar y poner en operación.

\section{Ampliar la ciudadanía universitaria según lo estipulado por el Artículo 5 de la Propuesta Democrática - Alternativa}

Las condiciones y los propósitos de una ampliación eficaz del ejercicio de la ciudadanía de los trabajadores universitarios, principalmente para el caso de los académicos, que subyacen respecto de lo estipulado en la Propuesta Democrática - Alternativa, continúan vigentes. Se trata de una necesaria reforma del Estatuto Orgánico.

Calcular los resultados de las elecciones institucionales según el cálculo establecido en el Artículo 6 de la Propuesta Democrática Alternativa

Se trata de un mecanismo que se fundamenta en la existencia de un sujeto colectivo y que sustituye (asumiendo la vigencia del voto universal) lo que hoy hace el TEUNA con el "voto ponderado" para calcular el resultado de una elección. Para ello, tal vez solo sea necesario cambiar el Reglamento del Tribunal Electoral Universitario.

\section{Establecer el grado de doctor como requisito para obtener en propiedad cualquier puesto académico en la Universidad Nacional}

La búsqueda permanente de la excelencia académica no es en nada contradictoria con los procesos de democratización en el seno de la comunidad universitaria. Pero se trata de fenómenos de distinta naturaleza. La excelencia académica demanda las más altas calificaciones de los trabajadores académicos; el grado de doctor es, en realidad, un mínimo para empezar una carrera de docente o investigador universitario. Como Universidad Pública, 
como Universidad Necesaria, la Universidad Nacional entonces puede cumplir un papel democratizador de enorme trascendencia en la sociedad costarricense si realmente se compromete, de forma seria, a hacer realidad los Principios, Valores y Fines estipulados en el Estatuto Orgánico. Pero este papel democratizador pasa por exigirse en la Universidad los más altos estándares académicos. Un buen profesor interino podrá seguir trabajando indefinidamente para la Universidad; pero para aspirar a una plaza en propiedad debe contar con el doctorado. Y en los puestos de elección popular, si es del caso, habrá simplemente que levantar impedimentos hasta tanto no se dé, como debe ser, que todos los académicos tengan grado de doctor.

Los primeros tres cambios vienen a ampliar y profundizar la ciudadanía en la pequeña república universitaria, mientras que el cuarto contribuye al logro de la excelencia académica que, definitivamente es un elemento de profundización democrática.

\section{Bibliografía}

Bartra, Armando. 2007. «Reseña de al libro de Héctor Díaz-Polanco, Elogio de la diversidad. Globalización, multiculturalismo y etnofagia». Revista Mexicana de Sociología 69 (1): 185.

Cruz Meléndez, Carlos, Jorge Guardado Torrez, Carlos Horta Valenzuela, William Páez Ramírez, y Leiner Vargas Alfaro. 2013. «Propuesta Democrática - Alternativa para un nuevo Estatuto Orgánico». Ponencia presentada en el IV Congreso Universitario, Universidad Nacional, Heredia, Costa Rica.

Díaz Polanco, Héctor. 2006. Elogio de la diversidad: globalización, multiculturalismo y etnofagia. Siglo XXI editores, México.

Gallardo Martínez, Helio. 2008. Crítica social del principio de agencia. Recuperado de: http://heliogallardo-americalatina.info/index.php? option=com content $\&$ task=view\&id=114\&ltemid=9

Gallardo Martínez, Helio. s/f. A propósito de la democracia: Grupo Democratización y democracia en América Latina, 2004/2010. Acceso el 2 de setiembre de 2017. http://www.heliogallardo-americalatina.info/index.php? option=com_content \&view=article \&id=197\&catid=11\&ltemid=106

Kant, Immanuel. 2006. Crítica de la razón pura. Editorial Taurus (Santillana Ediciones Generales, S. A.), México.

Lenin, Vladímir Ilich. 1985. «Sobre la caricatura del marxismo y el 'economismo imperialista'». Obras Completas: Tomo 30. Editorial Progreso, Moscú.

Marcuse, Herbert. 2014. El hombre unidimensional. Editorial Ariel, Barcelona, España. 
National Archives. 2015. La Declaración de Independencia 4 de julio de 1776. Acceso el 14 de setiembre de 2017. http://www.archives.gov/espanol/ladeclaracion-de-independencia.html

Ramírez Cardoza, Lorenzo. 2015. Movimiento Estudiantil de la UNA: Hora Cero. Acceso el 17 de setiembre de 2017 http://es.scribd.com/doc/265368641/Movimiento-Estudiantil-de-La-UNAHora-Cero

TEUNA 2015. Datos de elecciones 20052010 2015. Universidad Nacional. Heredia, Costa Rica.

Universidad Nacional. 2015a. «Estatuto Orgánico». Gaceta Ordinaria No 82015, al 20 de abril de 2015. Universidad Nacional, Heredia, Costa Rica.

Universidad Nacional. 2015b. «Reglamento del Tribunal Electoral Universitario (TEUNA) ». Alcance $N .^{\circ} 1$ a la UNA-GACETA 16-2015. Universidad Nacional, Heredia, Costa Rica. 